\title{
PROSUMIDORES \\ TECNOLÓGICOS, EDUCACIÓN Y CULTURA 2.0
}

\author{
ECHNOLOGICAL PROSUMERS, EDUCATION AND 2.0 CULTURE
}

\section{DARÍO ROCHA}

Profesor de la Universidad del Atlántico (Colombia).rochasolo@gmail.com

\section{RESUMEN:}

Este artículo reflexiona sobre la hipótesis de que los proponentes conectados a internet crean acciones y resistencias hacia las políticas globales y globalizantes con ejemplos en los que las colectividades - conectadas generan presión sobre las políticas estatales y las políticas culturales, posicionando modelos de gestión civil donde antes solo existían directrices institucionales. Entre los nuevos actores se destaca la figura del prosumidor, una forma evolucionada de la división productor - consumidor, quien los sintetiza en una sola persona, es decir, un individuo que produce y consume lo que produce, y al "ofertarlo" muchas veces lo hace sin ánimo de lucro. Este texto propone no desoír las tendencias y apoyar que la educación artística, sin olvidar de llevar el tema del desarrollo de habilidades creadoras y el ejercicio de la búsqueda y aceptación de nuevas estética, y sin olvidarse de las técnicas, bien podría decantarse en nuestro país por orientar la construcción de ecosistemas sostenibles de producción cultural, movilidad de intangibles y la promoción de prosumidores que revuelvan y resuelvan los mercados y visibilicen nuestros activos culturales.

\section{PALABRAS CLAVE:}

Arte, diseño, educación, educación artística, tecnología, cultura digital, prosumidor

\begin{abstract}
:
This article reflects about hypothesis that internet users have created new human actions and resistance to global and globalizing policies with examples where communities generate - connected pressure on state policies and cultural policies by placing civilian management models where before there were only institutional guidelines. Among the new players figure prosumer who is an evolved form of producer division stands out - consumer who synthesizes an individual who produces and consumes what it produces, without profit frequently. This text proposes not ignore the trends and support arts education without forgetting to bring the issue of the development of creative skills and exercise of search and acceptance of new aesthetics, without forgetting the techniques well in our country could opt for guide the construction of sustainable ecosystems of cultural production, mobility and promotion of intangible prosumers and solve that stir the markets and make visible our cultural assets.
\end{abstract}

\section{KEYWORDS:}

Arts, design, education, technology, artistic education, digital culture, prosumer 


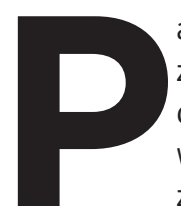
alabras como merchandising, mercados atomizados, clientes "V.I.P" y clientes "always on", clúster, apertura de mercados, posicionamiento web, marketing social y marketing geolocalizado, monetizar, etc., son conceptos a veces tan ajenos a nosotros y nuestra realidad diaria, mientras, por otro lado y al mismo tiempo, conceptos como GPS, comunidad virtual, redes virtuales, smartphone, tablet, browser o buscador, online, e-mail, e-comercio, e-learning son palabras tan comunes que se han incorporado rápida y radicalmente en nuestros discursos en cualquier ramo del saber, que nos hacen cavilar ¿Cómo funcionan?, ¿Cómo es que no nos damos cuenta del accionar de las primeras? 0 nos planta nuevas dudas, como: ¿Seguiremos siendo lo que somos o lo que queremos ser, o lo que la tendencia del mercado imponga? Si bien es cierto hoy día hay inteligentes formas de canalizar la producción de bienes bajo el esquema Win - win del sistema financiero y muchas empresas, incluidos algunos medios de comunicación, hablan y promueven la concientización del hombre como consumidor planetario, realmente se le ha relegado y aún se espera que sea la escuela la que brinde la oportunidad a la especie humana de seguir actuando como seres humanos.

Pensando en estas palabras y en la frase de Heidegger que encabeza este texto, deseo desarrollar la siguiente reflexión:

No es lo mismo cultura de consumo que cultura y consumo o consumo de cultura; cada una indudablemente nos planta en zonas de conocimiento diferentes con diferenciales y nuevos conceptos que nos arrastrarán a posiciones sobre temas económicos, o de plusvalía, sin que la mayoría de ellas esté ligada, excepto tangencialmente, con el término y lo que pretendemos que sea el vocablo "cultura", entendiéndola como aquel tema humano que reflexiona sobre problemáticas como patrimonio, desarrollo, educación, artes, ciencia, solidaridad, avance social, y desarrollo sostenible, etc.

Muchas personas buscan un buen concepto de cultura y concluyen que para sus labores en humanidades u otras ciencias es importante la definición dada por la Unesco en México:

\footnotetext{
"La cultura es el conjunto de rasgos distintivos, espirituales, materiales, intelectuales y afectivos que caracterizan una sociedad o grupo social, Ello engloba además de las Artes y las Letras. Los modos de vida, los derechos fundamentales del ser humano, los sistemas de valores, las tradiciones y las creencias". (1982, p. 1)
}

Estas frases se problematizan un poco debido que como propuesta de definición es anterior al nacimiento de la red de redes, que oficializó su nacimiento en 1983 cuando ARPANET se separa de la red militar que le dio origen y comienza a ser más pública. Debido a lo cual estamos ante una interesante coyuntura que incluso fue esbozada en las palabras que sirvieron

de antesala a esa misma definición en aquel famoso escrito:

\begin{abstract}
"El mundo ha sufrido hondas transformaciones en los últimos años. Los avances de la ciencia y de la técnica han modificado el lugar del hombre en el mundo y la naturaleza de sus relaciones sociales. La educación y la cultura, cuyo significado y alcance se han ampliado considerablemente, son esenciales para un verdadero desarrollo del individuo y la sociedad". (Unesco, 1982, p. 1).
\end{abstract}

Treinta años nos separan hoy de la propuesta conceptual de la Unesco, y esta distancia temporal nos enfrenta a la redefinición forzosa de la misma, planteándonos que aún nos sigue faltando la fuerza educativa que permita entablar el diálogo con estos y nuevos contextos a propósito de lo humano.

Luego de este tiempo y en la aventura que ha resultado ser el mundo conectado aparece hoy con fuerza un nuevo apelativo, muy popular en el seno del usuario tecnológico promedio, llamado "la cultura 2.0", hija de la llamada web 2.0 o la red social (Facebook, Flickr, Google plus, YouTube, Twitter, Linkdein, Myespace, redes P2P o peer to peer, las FTPs, etc). Cultura 2.0 propone un contexto donde existe una relación horizontal entre todos los proponentes conectados a Internet, homogenizando sin categorías a productores de bienes culturales, estructuras estatales y consumidores de los mismos, quienes hoy tienen la posibilidad de co-crear o semi-administrar la asimilación o la movilidad de estos bienes culturales. Por consiguiente, no es posible hablar en los mismos términos, ni en las mismas circunstancias de una sociedad pre Internet y la misma sociedad con Internet, y menos si esta dice 2.0 lo cual es un apelativo más que conocido cuando se liga el papel preponderante del uso del computador y la interconexión de redes con eventos y decisiones humanas; actualmente hablamos con suficiencia de la política 2.0 (visibilizada por la campaña digital y el gobierno en línea de Barack Obama) de la revolución 2.0 (visibilizada por los grupos de los indignados y los movimientos norteafricanos), incluso de la pornografía 2.0 (visibilizada por la oferta del sexo sin sexo a través de la webcam). Dándole ese alias como impronta de que se ha desarrollado bajo la perspectiva de cambios profundos y quizá irreversibles en la vida y la interacción del ser humano que se expresa a través de un computador. $Y$ debemos decir cambios con mayúscula porque al inicio del segundo decenio del siglo XXI muchas cosas se han trasformado gracias a la tutela de la interconexión de redes; muchos de los conceptos con los que nos comunicamos a diario han adquirido nuevos sentidos solo en nuestra sociedad, llegando a cambiar sus elementos políticos, sus resistencias, la humanidad que hemos construido o dejado de construir, los encuentros y desencuentros y las formas expresivas como nos hemos manifestado; asimismo, ha planteado nuevas maneras de acercarnos a la tecnología, no- 
vedosos aparatos con la que los administramos y la influencia de nuevos medios. Vemos que conceptos como arte, cultura, violencia, educación o comunicación se han redefinido, se han refundado; sobre todo en la manera como la individualidad y el colectivo se "conecta" y "por qué se conecta" con su semejante además de cómo interactuamos y decidimos como grupo humano. En nuestra historia hemos pasado de unas formas de reunión cerradas y de individuos similares a otras esferas de opinión y encuentro incluso multitudinarios, donde los participantes pueden ser menos semejantes entre sí; hemos pasado del ágora o plaza pública a la iglesia, de la iglesia a los grupos de reunión especializados (clubes o similares) y de estos a la Internet, mientras la máquina hoy más que nunca nos seduce y nos arrebata, incluso evolucionando en su propia renovada visión: de la odiada máquina dura de los 40 a los 80 , que fue vista como peligrosa, ominosa e inclusive castradora de la humanidad, para dar paso a la captación pasiva de la nueva máquina, de la máquina blanda en la que creemos: la ecológica, la plateada (cibernética), la liviana, la que ayuda, la que protege, sometiendo y tomando control del mercado simbólico, a través de su autoimagen, fundiendo, mezclando, dejándonos sin espacios identitarios y sin lugar interior.

Es apenas lógico, entonces, que más de una idea se balancee en la cuerda floja conceptual en la que estamos embarcados todos, y comiencen a mecerse asimismo sus relaciones en un sinfín de posibilidades:

- Sociedad de consumo - economía de mercado - cultura 2.0.

- Patrimonio - sociedad de consumo - cultura 2.0.

- Educación - consumo de cultura - cultura 2.0.

- Sociedad de consumo - consumo de cultura - cultura 2.0.

- Patrimonio - economía de mercado - cultura 2.0.

No obstante, nótese que cada concepto por separado suele apuntar a diferentes focos, y es necesario tener en cuenta que cada uno de ellos puede incluso deslindarse autónomamente de los otros, debido a que aproximadamente desde hace 50 años nos hemos permitido satanizar lo suficiente tanto sobre sus alcances como sus objetivos y sus formas de conocimiento, como sobre sus relaciones y sus contenidos como corpus teórico, donde entran en juego los temas, subtemas y sus términos. Aunque también es cierto que algunas personas aún no son conscientes de que incluso sin salir de la casa se encuentran atrapados en un mundo convulsionado donde se redefinen constantemente sus elementos básicos y donde propuestas fundamentales sobre la vida se presentan a diario como "bienes de consumo a la medida", o reflexiones que deberíamos hacer sobre el quehacer humano son presentados o disfrazados como "productos necesarios", con llamativos eslóganes, formas y colores que nos bombardean, nos seducen 0 nos oprimen, con diferentes tipos de ofertas y un sin número de "facilidades para la vida".
Desde el punto de vista anterior, lo que debemos encarar es que hemos crecido bajo la tutoría de los medios, que tienen por negocio movilizar el mercado y orientar el comercio, de manera que el concepto de lo formativo, lo educativo o el intercambio de aprendizajes parecen no estar en la ecuación, o por lo menos no en las primeras líneas, y basado en tal premisa propongo releer el texto La imagen matriz de Kroker (2004), que podemos resumir en su famosa frase "Lo analógico está siendo enterrado y lo digital baila sobre su tumba", debido a que más de lo que tal vez se reconozca en los metarelatos de la era digital, ya no estamos por más tiempo en una cultura dominada por la imagen, sino que somos pura imagen; con otras palabras, y cito a Yáñez (2007): "la distancia se ha perdido en la corrección óptica sustentada informáticamente. Cuando todo es susceptible de ser digitalizado, nada queda en la lejanía sino que es posible de ser alcanzado en cualquier nodo de la red" ; situación que nos ha convocado a replantear la relación enseñanza-aprendizaje en la que desventajosa y unilateralmente los docentes hemos quedado con el rótulo de análogos $\mathrm{y}$, por tanto, redundantes.

La Internet, más que ningún otro fenómeno social, ha desestructurado, reorganizado, renovado, construido e incluso destruido barreras o limitaciones en los grupos humanos. En el texto "La hipótesis imaginativa", Marcelo Expósito (2002) ,plantea que estos grupos humanos crean nuevas acciones y resistencias hacia las políticas globales y globalizantes y muestra a través de ejemplos en Europa, Asia menor, y muy recientemente en norte de África, como a través del llamado "efecto Túnez", las colectividades-conectadas generan presión sobre las políticas estatales y las políticas culturales, posicionando modelos de gestión civil donde antes solo existían directrices institucionales.

En la historia del hombre que consume que se corresponde con la historia de la supervivencia humana se le da sentido a los elementos consumidos y poseídos individual y colectivamente, sin embargo, cada vez más se plantea un contexto de ventaja económica y de movilidad global a la que debemos afrontar desde la educación con énfasis en la cultura. Debemos hacer hincapié en que el ser humano no puede estar alejado del contexto donde hay consumo, pero sí es posible apartarse del consumismo como práctica, es decir, alejarse de la experiencia degenerada de captación de bienes innecesarios para la vida, que en algunas partes de la historia se definió a través de la diferencia entre la opulencia de los ricos y marginalidad de los pobres, pero que hoy día podría ser considerada incluso "una enfermedad", dado su antominia con los estados saludables propios del ser humano.

"A nivel político, el nuevo paradigma colaborativo de la fase segunda de la web que protagoniza esa multitud conectada que se expresa y comparte sus creaciones en las redes es uno de los más claros
69 
pasos hacia la existencia efectiva de un modelo social que considera a la democracia de la multitud (siguiendo muchas de las propuestas de Occam, Marsilio de Padua o Spinoza, entre otros) como la forma absoluta de la política. Aceptando este posicionamiento, la multitud conectada, infinita multiplicidad de singularidades activas, podría ser considerada, en sus potenciales más emancipatorios y creativos, como el origen de una política no "sobre" la vida sino "de" la vida, es decir, una clara muestra de la introducción de "la potencia de la vida" en la política". (Prada, 2000, p.6)

En este caldo de cambios y tensiones nace una nueva figura... la del "prosumidor", que en la economía del conocimiento (no en la economía de mercados) es una forma evolucionada de la división productor - consumidor, quien los sintetiza en una sola persona, es decir, un individuo que produce y consume lo que produce, y al "ofertarlo" muchas veces lo hace sin ánimo de lucro. Al oír esto inmediatamente nos encontramos ante una paradoja: en contextos neoliberales, capitalistas y de consumo se están desarrollado actividades contrarias que redefinen las interacciones de poder $\mathrm{y}$, por ende, las relaciones humanas; un ejemplo de ello es que los jóvenes se mueven sin prisa pero con agilidad en las redes sociales y parecen estar omnipresente en nuestros días aportando gratuidad al comercio de algunos bienes sin monetizar; ni la movilidad de los mismos, ni la tenencia de los bienes de consumo en acciones que han llegado a ser lugar común: pasar música, fotos, videos, imágenes, libros, creaciones cercanas al arte, etc.

Ser un prosumidor en la actualidad es tener la oportunidad de salirse un poco de la cadena de producción de las multinacionales, de sus maquinarias de consumo, de sus imposiciones arancelarias y de sus desmanes culturales; ser un prosumidor con uso de la tecnología implica una nueva aceptación de una economía personal basada en la oferta individualizada y personalizada de bienes en una sociedad globalizada y tecnológicamente avanzada.

Los prosumidores aumentan el crecimiento económico al buscar nuevas formas de mercado aprovechando las plataformas existentes o creando nuevas. Con otras palabras, las nuevas generaciones cada vez más tienen como imperativo categórico encontrar las formas de vincular sus emociones y saberes al beneficio prácticos de su comunidad y de su propia estabilidad económica; cada vez más sabemos que necesitamos innovar para conseguir recursos y que estos están precisamente en aquellas actividades que nos resultan agradables. El joven de hoy no puede "ver pasar la vida esperando la oportunidad que le nombró el padre" sino afrontar con dignidad las posibilidades que hoy por hoy le brinda la sociedad.

De esta manera, la tensión entre las ofertas prodigadas por el incremento en la pulsión de la actividad web, las tendencias consumistas promovidas por las grandes empresas privadas, las reordenaciones de las políticas de masas y la afirmación del prosumidor como nuevo miembro consciente del mercado propone unos nuevos elementos educativos que permitan al novel actor de la sociedad moverse sin precipitación y al tiempo propender por el desarrollo. Este por su lado, no debe basarse solamente en la buena intensión de un grupo de personas sino que debe sostenerse desde unas políticas que incluyan el desarrollo cultural que permitan el diseño de una realidad cultural futura a corto y largo plazo, asistido por un modelo de democracia cultural, en tanto que el basamento no sea solo sustentado ni dirigido únicamente por el estado. $Y$ en este sentido, las instituciones educativas de todas las edades, desde los colegios de básica primaria y media e incluso las universidades, aún vemos temerosos las posibilidades de la aplicación, circulación y utilización de valores culturales que revitalicen el patrimonio tangible, oral e inmaterial y hagan fuerte el tejido social de nuestro país, dejando de tomar partido en muchas ocasiones esperando la directriz gubernamental.

Mantenemos, entonces, la misma expectativa que alimenta la educación desde que somos conscientes de este proceso: ¿cómo educar?; adaptando la pregunta solo a los cambios de forma presentes en este disertación: ¿Cómo educar en la actualidad al joven para que sea prosumidor, entre tantas estrategias promocionales elaboradas sistemáticamente para crear consumidores-pasivos?, ¿Cómo promover al joven prosumidor si en ocasiones algunos de nuestros docentes todavía sienten resistencia sobre la palabra consumo?, son tantas cosas que los docentes deberíamos limar para hablar de estos temas directamente con los jóvenes, que necesitamos una revolución digital más agresiva y profunda entre nosotros, que no se limite a ver el internet en las cosas, o la pedagogía del uso del computador por partes y componentes, sino que brinde herramientas de inmersión en las políticas que subyacen en el ejercicio de la opinión, el debate y el encuentro con otros en las redes, con recursos para docentes que le permitan ejercer a plenitud su ciudadanía digital.

La mayoría de estos prosumidores, que han encontrado incluso muy jóvenes un nicho de mercado digital y su sustento diario, basan su actividad en lo artístico (la producción de música fuera de los círculos de las casas disqueras, los fotógrafos que desean mostrar sus creaciones en lugares diferentes y alternos además de la galería de arte, el artista, caricaturista, creador de videos, renderizados, maquetas digitales, que ve en las redes sociales sobre todo una alta demanda de asiduos y potenciales canjeadores de bienes), de manera que parece lógico que los creativos en mayor medida se convierten rápidamente en prosumidores, mientras que aquellos que no tienen filtros de consumo se convierten en los consumidores pasivos y en partes de engranes de la gran masa consumista. 
La educación artística, sin olvidar de llevar el mundo del arte al ámbito educativo y viceversa, con todo el tema del desarrollo de habilidades creadoras y el ejercicio de la búsqueda y aceptación de nuevas estética, y sin olvidarse de las técnicas, las pinceles y los colores, bien podría decantarse en nuestro país por orientar la construcción de ecosistemas sostenibles de producción cultural, movilidad de intangibles y, sobre todo, promover prosumidores aguerridos que revuelvan y resuelvan los mercados y visibilicen nuestros activos culturales, no solo para su disfrute, sino para su permanencia y su introyección como bien público, en términos de la economía contemporánea.

En este punto me imagino que parte del público con funciones docentes dirá: ¿Pero cómo es posible que deseen ponerle más aretes a la ya cargada oreja del arte en la escuela? Y la respuesta es tan sencilla como que no es algo que proponga yo como individuo, por el acaso de estar aquí en el día de hoy, sino que son las tendencias educativas y los nuevos paradigmas que se cruzan y forman bordes suaves entre las parcelas del conocimiento; aunado a las condiciones actuales del hombre enfrentado a los artículos de su creación y los empujes del ser humano sobre sí mismo, quien nos obliga a prestar atención a estos y otros detalles en la escuela, y sobre todo desde la educación artística, que está llamada a ser la gran interlocutora del siglo XXI, debido a que más que nunca la interacción con interfaces cargadas de imágenes, sonidos y performances están entre nosotros a cada instante de la vida y conceptos como la apreciación estética, el diseño, el manejo de la visualidad se han convertido en habilidades y destrezas básicas del ciudadano común.

Quizá algún otro pregunte: ¿Pero, entonces, cómo podrá realizarse todo aquello? Y la respuesta no tan sencilla será: como docentes muy observadores del medio, sobre todo personajes bien informados y en lo posible prosumidores, de manera que nuestros estudiantes se decanten por prácticas saludables de consumo desde la creatividad del maestro en desenvolverse en este mundo que nos ha tocado vivir.

Para terminar, parafraseando la cita de José Ortega y Gasset, "Mientras el tigre no puede dejar de ser tigre, no puede destigrarse", el hombre vive en riesgo permanente de deshumanizarse. La educación artística favorece la integración de lo humano y lo educativo en niveles incluso insospechados; permite ver la integración del hombre en una sociedad que parece privilegiar la soledad, la falta de careo, la emoticonización, en vez de sentimientos reales, donde parece que se privilegia la palabra o el concepto amigo antes que la persona que ostenta el título; es la oportunidad que tenemos para no deshumanizarnos, para no perdernos en el valle de siliconas y datos. Educar la mirada y cómo y desde cuándo y quiénes o con quiénes, entonces ha de ser un compromiso ético que debería asumirse desde la escuela y no meramente desde la institucionalidad gubernamental (o por lo menos no solamente gu- bernamental, para evitar su sesgo potencialmente comercial), entendiéndose que la cultura en general o el conjunto de sus elementos "plantan ideas", es necesario prever los espacios cada vez más escasos que tiene el hombre con su propia determinación, su propia autoconciencia y su autoreconocimiento como ser finito.

\section{REFERENCIAS BIBLIOGRÁFICAS}

Atochero, A. (2009). Ciberantropología. Cultura 2.0. Editorial UOC. Castells, M. (2004). Era de la información: economía, sociedad y cultura. México: siglo XXI.

Michaud, Y. (2007). El arte en estado gaseoso. México: Fondos de Cultura Económica.

Rousseau, B. (1999). Instrumentos teóricos y metodológicos para la gestión cultural. Barranquilla: Universidad del AtlánticoFondo Mixto.

Walker, J. A. (2002). Una introducción a la cultura visual. Barcelona: Octaedro-EUB.

Ramírez, J. A. y Carrillo, J. (2004). Tendencias del arte, arte de tendecnias a principios del siglo XXI. Madrid: Ensayos Arte Cátedra.

\section{Documentos Online:}

Expósito (2002) Recuperado el 09 de 05 de 2012, de http://marceloexposito.net/pdf/exposito_desobediencia.pdf

Kroker, A. K. (2004). Recuperado el 09 de 05 de 2012, de

http://aleph-arts.org/pens/imagen_matriz.html

Portal Unesco. (1982). Recuperado el 09 de 05 de 2012, de http://portal.unesco.org/culture/es/ files/35197/11919413801mexico_sp.pdf/mexico_sp.pdf

Prada (2000) Recuperado el 09 de 05 de 2012, de http:// www.estudiosvisuales.net/revista/pdf/num5/prada_20. $\mathrm{pdf}$

Martínez (2003) Recuperado el 09 de 05 de 2012, de http:// www.estudiosvisuales.net/revista/pdf/num7/07_sergiomluna.pdf

Yañez, G. (2007). Recuperado el 09 de 05 de 2012, de http://www.estudiosvisuales.net/revista/pdf/num5/ yanez_imagen_dig.pdf

\section{FORMA DE CITAR ESTE ARTÍCULO}

Rodríguez Miranda, J.P. \& Galvis Peñaranda, V.F. (2014). Dos variables para el equilibrio fundamental entre el ser y el ambiente. Revista Arte y Diseño Facultad de Arquitectura, Arte y Diseño, Universidad Autónoma del Caribe, Barranquilla. ISSN 1692- 8555 Vol. 12 (N.1). P.P 39 - 44 